\title{
Numerical Simulation of Turboexpander for Geothermal Energy ORC Power System
}

\author{
Bing-Cheng LIU ${ }^{1, a}$, Xi-Bao DONG ${ }^{2, b,{ }^{*}}$, Lu-Hang WU ${ }^{3, c}$, Kui CAO ${ }^{4, d}$ and \\ Quan-Min WANG ${ }^{5, e}$ \\ ${ }^{1,2,3,4}$ Qingdao University of Science and Technology, College of Electromechanical Engineering, \\ Qingdao 266061, China \\ ${ }^{5}$ Shaanxi Blower (Group) Co.,LTD. Shaanxi 710000, China \\ abingchengl@163.com, ${ }^{b} x i b a o d o n g @ y e a h . n e t, ~{ }^{c} 1296757410 @ q q . c o m,{ }^{d} 447477103 @ q q . c o m,{ }^{e} 23$ \\ 12064073@qq.com \\ *Corresponding author. Tel./fax: +008618563929801.
}

Keywords: Geothermal energy; ORC power system; Turboexpander; Structure optimization.

\begin{abstract}
In this study, a turboexpander for geothermal energy ORC power system was desgned. R245fa was selected as the working fuild. The factors which influence the performance of the trubine were analyzed and discussed. The software Ansys-CFX is used to perform preliminary steady-state CFD simulations. The results demonstrate that in about 30\% relative chord length near the rim area, the working fluid flow direction has a greater turning direction, and there has a big produced entropy region by the local low-energy group within rim wall. The loss was further increase at the trailing edge of the impeller exit, there are several reasons to cause this phenomenon, such as the loss of low velocity flow stream, the main fluid mixing effect and part of the mechanical energy is converted to heat the working fluid. A smaller wheel diameter ratio and larger meridional flow channel width within reasonable range of values can reduce flow loss and improve the efficiency of the expander.
\end{abstract}

\section{Introduction}

Radial turbine expander has good prospects in the Organic Rankine Cycle system. For low temperature heat source recycling, the use of radial turbine expansion machine can achieve a higher conversion efficiency. The aerodynamic structure design of the rotor blade affects the thermal efficiency, the enthalpy drop and the stability and efficiency of the radial turbine expander. Rohlik[1], Rodgers[2] and Baines[3] established the energy loss model of the rotor balde to design the high-efficiency expander. Penget al.[4] designed the rotor balde by using the method of parabolic processing. By means of numerical simulation it is proved that the design efficiency is higher.By using the finite volume method and application of 3D design theory,Feng Zhen et al.[5] designed centripetal type turbo expander.Then he studided on the flow characteristics of working fluid in meridional channel.The quasi three dimensional design method was applied to the design of the air turbine expander by Zhang et al.[6],and the design calculation process was verified by the whole 3D design method.

In the present paper, $50 \mathrm{~kW}$ turbo expander was designed.The refrigerant $\mathrm{R} 245 \mathrm{fa}$ is chosen as the working fluid for the radial turbine expander. The turbo expander impeller was optimized.

\section{Optimization Design of the Impeller of the Turbo Expander}

Five sets of tests were respectively corresponding to the main geometrical dimensions of the five impeller type as shown in Tab 1 . Case1, case2, case3, case4, case5 were respectively corresponded to different impellers. Comparison of impeller blade type is presented in Fig.1. 
Tab 1 The main dimensions contrast between five different impeller

\begin{tabular}{|l|l|l|l|l|}
\hline $\begin{array}{l}\text { Test } \\
\text { number }\end{array}$ & $\begin{array}{l}\text { Impellers } \\
\text { number }\end{array}$ & $\begin{array}{l}\text { Rotor exit radius } \\
\text { at hub(mm) }\end{array}$ & $\begin{array}{l}\text { Rotor exit radius } \\
\text { at tip(mm) }\end{array}$ & $\begin{array}{l}\text { Meridional } \\
\text { channel } \\
\text { width(mm) }\end{array}$ \\
\hline 1 & case1 & 71 & 23 & 52 \\
\hline 2 & case2 & 81 & 28.5 & 61 \\
\hline 3 & case3 & 66 & 25 & 64 \\
\hline 4 & case4 & 75.5 & 27 & 72 \\
\hline 5 & case5 & 85.5 & 30 & 79 \\
\hline
\end{tabular}

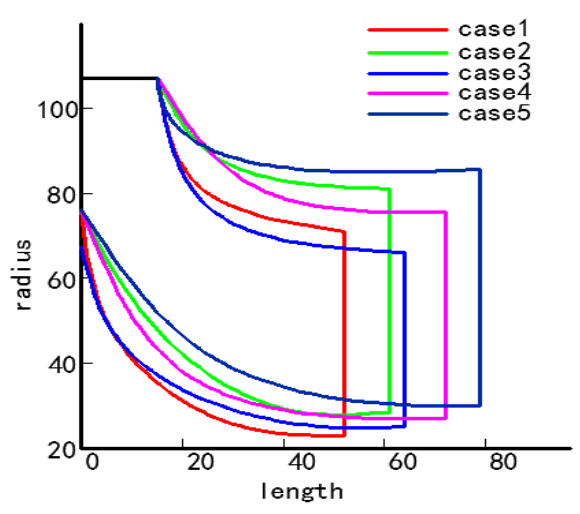

Fig.1 Five different sets of impeller blade contrast figure

\section{D Geometry}

The software ANSYS-Bladegen were used to define the 3Dgeometry of the turbine presented in Fig.2. The data from the preliminary $1 \mathrm{D}$ design were transferred intoANSYS-Bladegen, including amongst the most important parameters, radii and blade heights.

An annular diffuser at the exit of the rotor isfrom the 1D radii values. No optimisation was carried outon the 3D diffuser geometry. The nozzleshub and shroud contoursare defined asBezier curves.The nozzle hub and shroud thicknesses, the rotor blade angle and rotor thickness distributions wereiteratively adjusted using Bezier curves in order to achieve reasonnable preliminary results with blade-to-blade and throughflowsolvers notably in terms of loading and Mach numbers which weremaintained in the transonic region. The same thickness distribution was used for the stator hub and shroud while two separatedistributions were set for the rotor hub and shroud.

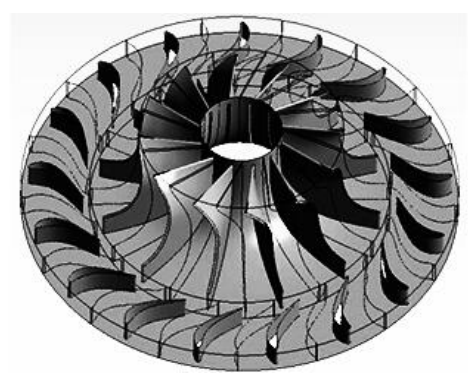

Fig. 2 The outline of three-dimensional turboexpander

\section{Three-dimensional Numerical Simulations}

\section{Mesh}

The software ANSYS-TurboGrid were used to generate mesh.The H/J/C/L-Gridthree-dimensional 
computational mesh for the simulation of one blade passage is shown in Fig.3 for the nozzle and in Fig. 4 for the rotor shround and hub respectively.The nozzle grid number is 247000 ,and the rotor is 536000. The topological structure is composed of a plurality of blocks, such as inlet part, outlet part and flow passage part,etc. Each block is controlled by its vertex, the control point. When the generatedgrid has a negative grid, the control point of the block can be adjusted. Then repeat the mesh generation process. Through the MeshAnalysis function to check the quality of the grid, until the optimal grid is obtained. The average non-dimensional grid spacing at the wall $\mathrm{y}^{+}<1$. Make sure that the first layer grid node is in a sticky bottom layer.

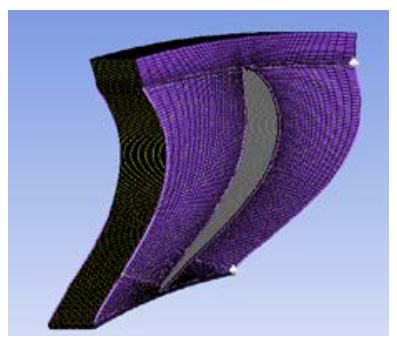

Fig. $3 \mathrm{D}$ view of the $\mathrm{H} / \mathrm{J} / \mathrm{C} / \mathrm{L}-\mathrm{Grid}$ grid around the stator blades

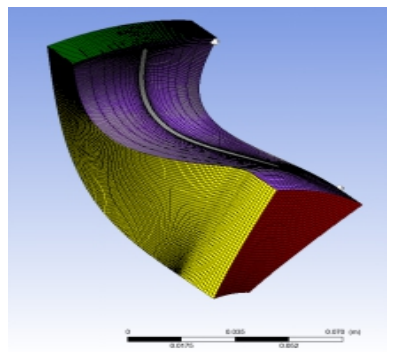

Fig. $4 \mathrm{D}$ view of the $\mathrm{H} / \mathrm{J} / \mathrm{C} / \mathrm{L}-$ Grid t grid around the rotor blade at the shroud

\section{Boundary Conditions}

Boundary and initialconditionswere set as shown in Table 2. A mixing plane condition was set at the interface between thestationary (stator) and rotational (rotor) frames and a frozen rotorinterface was set between the rotor and the diffuser. Periodicboundary conditions were appliedas only one blade passage for boththe stator and the rotor was modelled.

Tab 2 Boundary conditions of Nozzle and Impeller blade for 50kW turboexpander

\begin{tabular}{|l|l|}
\hline Initial conditions & type \\
\hline Nozzle inlet & inlet \\
\hline Rotor outlet & outlet \\
\hline Nozzle hub & no slip wall \\
\hline Nozzle shroud & conter rotatingwall \\
\hline Rotor hub & no slip wall \\
\hline Rotor shroud & conter rotatingwall \\
\hline Periodicity & periodic \\
\hline Interface & frozen rotor \\
\hline Turbulence model & SST \\
\hline
\end{tabular}




\section{Results and Discussion}

Five groups of uniform experimental results are shown in Table 3. From the table we can see that the five groups of uniform experimental arrangement is reasonable, the turbine expander efficiencyis quite different ,the minimum efficiency is $75 \%$, the maximum efficiency is $89 \%$.

Tab 3 Five groups of uniform experimental results

\begin{tabular}{|l|l|l|l|}
\hline Test number & $\begin{array}{l}\text { Impellers } \\
\text { number }\end{array}$ & $\begin{array}{l}\text { Wheel diameter } \\
\text { ratio }\end{array}$ & $\begin{array}{l}\text { Turbine expander } \\
\text { efficiency (\%) }\end{array}$ \\
\hline 1 & Case1 & 0.55 & 86.506 \\
\hline 2 & Case2 & 0.65 & 79.183 \\
\hline 3 & Case3 & 0.5 & 89.463 \\
\hline 4 & Case4 & 0.6 & 82.285 \\
\hline 5 & Case5 & 0.7 & 75.844 \\
\hline
\end{tabular}

Entropy production exists in turbo expander, available energy decreases, the turbo expander efficiency is reduced. Energy loss in impeller passage can beintuitiveobserved in the entropy image. Fig.5 shows the impellersoutlet entropy image. Suction side of the impeller blade is on the left side, and pressure side is on the right side.The impeller rotation direction is counter clockwise. By the entropy image we can find that: The entropy distributions of case 1 and case 3 are similar.Near the pressure side, there is the small area ofentropy production, the flow loss is less. On the pressure side near the rim side, the case 2 and case 4 have larger areas of large entropy production, and the areas of entropy productionincrease with the increase of blade height. These are mainly due to leakage loss ang local secondary flow. There is a large high entropy region in case5, flow loss in the flow channel is larger. In a reasonable range, the flow loss of impeller flow channel can be reduced by the smaller wheel diameter ratio.

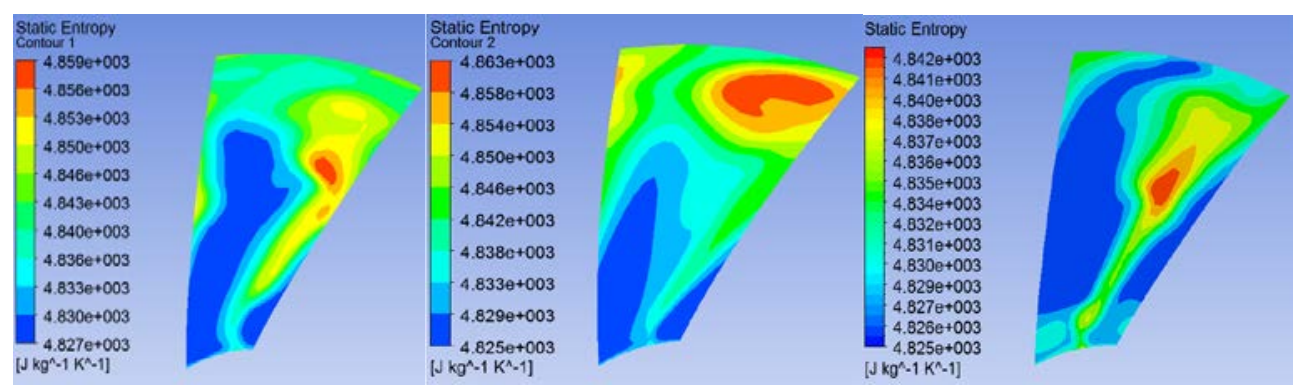

(a) case 1

(b) case2

(c) case3

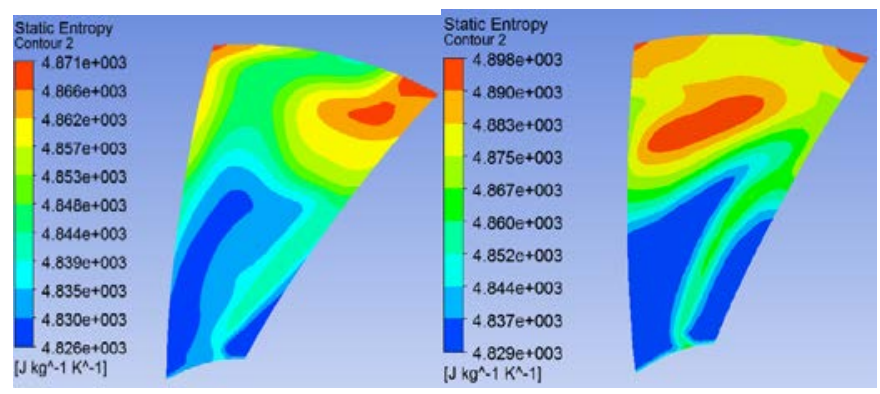

(d) case 4

(e) case5

Fig. 5 Entropy production contours in outlet section of impeller

The Mach number of impeller meridional is shown in Fig.6. The Mach mumber of case1 and case3 are silimar. Ther are two main regions of large mach number. One isin the $30 \%$ relative chord 
length near the rim area. There is a great turning point in the flow direction of the working fluid.The fluid velocity increases sharply, and the Maher number is about 1.3. Another is in the outlet trailing edge, which has largest angle of rim side and has highest impeller axial velocity. Thus the Mach number of rim side is much larger than that of hub side. Due to the larger wheel diameter radio of case2, the cross-sectional of the impeller meridional channel has a sudden change. Thus a larger Mach number is generated in the area, and the Mach number is about 1.5. The wheel diameter radio and meridional channel width of case 4 are respectively 0.6 and 72 . The reasonable collocation of the two factors makes the throat area of the impeller flow channel not have too large Mach number region. But in the outlet hub side, there is a large Mach number region. Due to the axial length of case 5 is larger, so the flow in the flow channel is relatively smooth.Just has a small range of high Mach number regionin the 30\% relative chord length near the rim area, on the whole, the meridional channel width is larger can improve the flow characteristics of working fluid, reduce the flow loss.

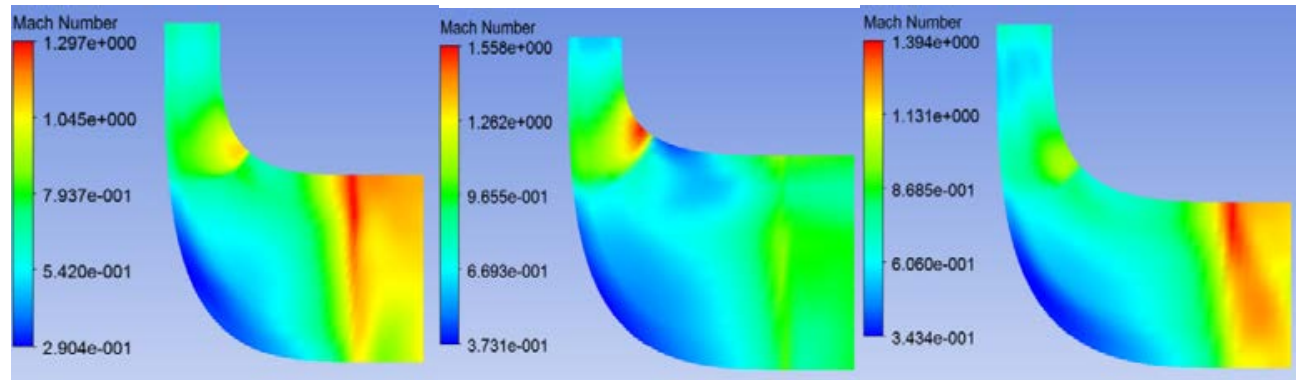
(a) case 1
(b) case2
(c) case3

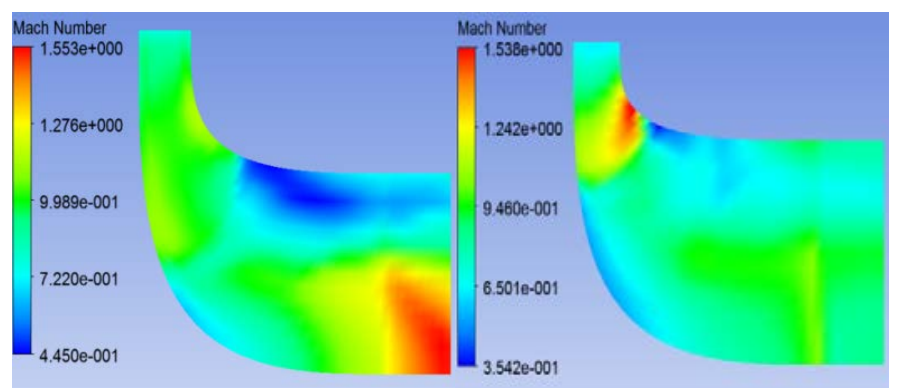

(d) case4

(e) case5

Fig. 6 Mach number contours in meridional section of impeller

\section{Conclusion}

In this paper, a radial flow turboexpander for ORC was designed. R245fa was chosen as the working fluid in consideration of its appropriate evaporation pressure and its satisfactory thermal stability. The software ANSYS-Bladegen were used to define the 3Dgeometry of the turbine and the software ANSYS-TurboGrid were used to generate mesh. Furthermore, commercially-available software Ansys-CFX is used to perform preliminary steady-state CFD simulations. Finally, the optimization of turboexpander impeller was completed. The 3D CFD results are presented and analyzed.

\section{Acknowledgement}

This research was financially supported by the Key Program of Department of Science \& Technology of Shaanxi Province(Grant No.2014KTZB03-02-03(2)).

\section{References}

[1] Rohlik H.E. Analytical Determination of Radial Inflow Turbine Design Geometry

for Maximum Efficiency. NASA report TN D-4384, 1968. 
[2] Rodgers C, Geiser R. Performance of a High-Efficiency Radial/ Axial Turbine. AMSE Journal of Turbo-machinery 1987,109(2):151-154.

[3] Whitfield A, Baines N.C.The Design of Radial Turbomachines. New York:John Wiley and Sons Inc 1990,5(4):199-326.

[4] Peng L, Gu C. Radial Turbine Blade Design and Internal Flow. Coal Technology 2010,29(8):12-15.

[5] Feng Z, Shen Z. Calculation Method and Characteristic Analysis of Three Dimensional Flow in Radial Turbine Impeller. Journal of Xi'an Jiaotong University 1994,28(1):107-115.

[6] Zhang W, Zou Z, Liu H, et al. Study on Turbine Aerodynamics Design of Small Turbofan Engines. Journal of Aerospace Power 2010,25(1):72-79. 